\title{
Political potholes in the roadmap for research
}

\author{
In the March for Science, held on 22 April in cities around the world, many placards bore Galileo's \\ assertion that scientific truth is unaffected by political circumstance, "Eppur si muove". But scientific \\ research is inevitably shaped by the political climate in which it takes place.
}

Science and politics cannot be separated. Nevertheless, recent elections and referendums worldwide have demonstrated a rise in populist ideologies that regularly eschew and dismiss the opinions of experts in general, and scientists in particular. The stifling effect of such political landscapes on scientific research is becoming all too apparent. The ongoing development of cannabis policy in the United States (US) typifies a new dimension in this debate.

Cannabis sativa is a versatile crop. The hemp fibres it produces make ropes, paper, textiles and building material; its seeds are used for food and produce oil that is a potential biofuel; and its complex secondary metabolism creates high-value molecules with medical potential. But research into such applications has to contend with regulations that overwhelmingly focus on its exploitation as a recreational drug.

Eight states of the US have legalized marijuana use within their borders, and a further twenty-one (plus the nation's capital) have affirmed its medicinal use. Many of these states have found tax revenues from the drug exceeding expectations without a significant rise in crime. Polls have shown public opinion on marijuana use changing dramatically in a matter of years, with a clear majority of Americans now believing that cannabis should be legalized for all uses, and that marijuana is less harmful than alcohol, tobacco and prescription opioids.

Despite public support and state-level activity, the federal government remains opposed to overhaul of existing laws, which continue to prohibit cannabis in any use or purpose. The new attorney general, Jeff Sessions, insists that marijuana has no benefit to individuals, is causing more violence than crime statistics reflect, and favours a Justice Department crack down on states that allow recreational use - a lawful stance, though one that the Obama administration declined to pursue.

However, a more consequential event regarding cannabis policy in the US may have happened under the Obama administration, when the Drug Enforcement Agency (DEA) last year declined to change or even advise to change the status of cannabis as a schedule I narcotic. Schedule I does not necessarily mean that cannabis is considered more dangerous than cocaine or oxycodone (schedule II), or anabolic steroids (schedule III), but rather that the government sees no medicinal value or acceptable medical use for it. As such, federal research money used for any study involving cannabis must be approved under very specific circumstances by multiple agencies. This dramatically slows research projects or forces a change in their subject matter.

Up until last year, all marijuana used in federal-funded research came from a single approved facility at the University of Mississippi, causing long waiting lists and complaints over the variety and quality of the cannabis supplied. The one alteration approved by the DEA last year was to allow more potential cannabis producers for research purposes, so that scientists can gauge the effects of different strains and species of cannabis.

That may not be enough, however, to truly change the face of cannabis research in the US. Colorado doctor Alan Shackelford researches the use of medical marijuana in treating seizures, but his studies are conducted in Israel due to its less restrictive policies affecting clinical studies. He would like to do his research in the US but for the continued intransigence of both public officials and agencies. "We have the best scientific community in the world here, and we're not allowed do research that can save lives?" he says. "To not pursue this information is illogical and causes harm for no reason." Cannabis is thus caught in a paradox: the government won't change its research policies for lack of evidence of a medicinal benefit, but the research into potential medicinal benefits is obstructed by those very government policies.

That a centre-left presidential administration, enjoying popular support from the public and with the backing of over half of the states in the Union, refused to change policies on this issue or press congress towards relaxing federal marijuana laws may have a more lasting effect on cannabis research than any potential legal fight between those states and the new administration. A feeling of 'if not now, when?' makes proponents and researchers sceptical about imminent policy changes. The issue did not come up during the 2016 US presidential election, leaving many voters with no idea how their choice might shape cannabis policy, both for research and usage.

"There's a considerable disconnect between public understanding of how the process works, and how political decisions may have an effect on them," Shackelford says. "The work I can do in Israel, it could take years to do that here in the US, and neither I nor my patients have that kind of time. The public loses out on medicines that could alleviate or even cure their illnesses because of politicians who have stances out of step with reality. This isn't something we discovered in the Amazon a month and a half ago; cannabis has been a mainstay of Western medicine from the beginning."

Young people in the US overwhelmingly support legalized marijuana and may force the issue as their electoral clout grows in the years to come. Anecdotal evidence grows daily about both the scope of cannabis production - free market economics driving increases in quality and variety - and its effectiveness against various ailments, further reinforcing public support for the plant. And this is before considering the environmental benefits of hemp for industrial and consumer purposes, also the subject of global research but facing roadblocks in the US. Meanwhile, Canada may soon become the largest country in the world to decriminalize the drug at a national level, paving the way for it to join multiple countries that have become de facto research hubs for cannabis scientists around the world who have bypassed their nation's borders and restrictive laws.

Politicians in many countries are running on isolationist platforms that will impede the kind of cooperation and openness that scientists need to work effectively. Those who argued that the March for Science could cause a backlash and that science should be separate from politics fail to see that research is already interconnected with policy decisions and electoral outcomes. These recent debates may prove a wake-up call for us to realize that the future of research is not just in the laboratory, but in legislatures, courtrooms and at the ballot box. 